\title{
Editorial
}

\section{Liquid Diagnosis of Hepatic Encephalopathy: Are We There Already?}

\author{
Mariana Verdelho Machado \\ Faculdade de Medicina, Universidade de Lisboa, Lisbon, Portugal
}

Keywords

Hepatic encephalopathy · S100 $\beta$ · NSE · Ammonia

\section{Diagnóstico líquido de encefalopatia hepática - já uma realidade?}

\section{Palavras Chave}

Encefalopatia hepática $\cdot \mathrm{S} 100 \beta \cdot \mathrm{NSE} \cdot$ Ammonia

Hepatic encephalopathy (HE) is a neurocognitive syndrome associated with liver disease and/or portosystemic shunts. Its diagnosis is clinical and requires exclusion of many other conditions that can present with similar neuropsychiatric abnormalities [1]. The broad differential diagnosis, and huge clinical overlap with many metabolic, neurologic and psychiatric disorders, is a challenge for clinicians that must decide in which patients further laboratorial, imaging and neurophysiological investigation is warranted.

As opposed to overt HE (OHE), minimal HE (MHE) curses with no clinical manifestations, and is diagnosed on the bases of abnormal results on psychometric and neurophysiologic tests [1]. Those tests are quite sensitive

\begin{tabular}{ll}
\hline KARGER & $\begin{array}{l}\text { (c) } 2020 \text { Sociedade Portuguesa de Gastrenterologia } \\
\text { Published by S. Karger AG, Basel }\end{array}$ \\
karger@karger.com & This article is licensed under the Creative Commons Attribution- \\
www.karger.com/pjg & $\begin{array}{l}\text { NonCommercial-NoDerivatives } 4.0 \text { International License (CC BY- } \\
\text { NC-ND) (http://www.karger.com/Services/OpenAccessLicense). } \\
\text { Usage and distribution for commercial purposes as well as any dis- } \\
\text { tribution of modified material requires written permission. }\end{array}$ \\
BOPEN ACCESS &
\end{tabular}

but are time-consuming, require training and may be affected by the patients' age and education, explaining why MHE is the most under-diagnosed form of HE, even though it can afflict up to $80 \%$ of patients with chronic liver disease (CLD) [2]. The lack of recognition of MHE may have important implications, since MHE associates with impaired quality of life, decreased ability to perform daily tasks, and increased risk for work and traffic accidents. Furthermore, MHE predicts the development of OHE and increased mortality [3].

Hepatologists' work would be easier if there were a simple serum biomarker that could identify accurately patients with HE, either OHE in the emergency room, or MHE in the outpatient clinic. It would also help, if that biomarker would correlate with severity of HE in order to objectively monitor response to therapy. Monitoring of therapy response would be most useful in the context of MHE, since, in the case of OHE, once diagnosis is established, clinical evaluation is more straightforward in assessing evolution of HE severity. A biomarker must be accurate, reliable, sensitive/specific, and provide high predictive value.

Ammonia is a serum biomarker that $60-95 \%$ of clinicians use in their practice to diagnose HE [4], although studies show, that in the context of CLD, ammonia determination does not seem to change the management of the 
patient, nor provides prognostic information [5]. Joint European and American guidelines state, however, that in a patient with OHE, a normal blood ammonia level should raise the suspicion of an alternative diagnosis [1]. Ammonia is an appealing candidate biomarker because of its role in the pathogenesis of HE. The first link between ammonia and HE was published in the work of Marcel Neucki and Ivan Pavlov in 1893, in portacavalshunted dogs with the so called "meat intoxication syndrome" [6]. More than 100 years after, ammonia is still placed in the centre of the pathogenesis of HE. Ammonia is mostly produced by the colonic microbiome from dietary proteins-derived nitrogen. Thereafter, $85 \%$ of ammonia is detoxified through the Krebs cycle in the liver and excreted in the urine as urea, whereas $15 \%$ is metabolized in the muscle and brain through the synthesis of glutamine from glutamate. CLD is prone to hyperammonemia, with colonic dysbiota increasing ammonia production and decreased ammonia detoxification as a result of hepatocellular dysfunction, portosystemic shunts and sarcopenia. Hyperammonemia can be toxic to the central nervous system, promoting the development of HE. In the brain, detoxification of ammonia occurs in astrocytes, through glutamine synthetase with conversion of glutamate to glutamine. Increased cellular glutamine has an osmotic effect, to which astrocytes respond realising osmolytes such as myoinositol and taurine to the extracellular space. This restores temporarily intracellular osmolarity, but increases susceptibility to subsequent cytotoxic cell edema. Neurons can uptake glutamine, being a precursor of excitatory glutamate and inhibitory $\gamma$-hydroxybutyric acid (GABA) neurotransmitters. In fact, hyperammonemia may induce cell death through excessive glutamate-induced $\mathrm{N}$-methyl-D-aspartic acid (NMDA)-receptor activation, as well as an increased GABAergic tone, transiently responsive to flumazenil [7]. Ammonia also impairs brain metabolism and promotes oxidative/nitrosative stress, promoting oxidation of RNA and proteins, which may explain multiple disturbances of neurotransmitter systems in HE. Albeit its role in the pathogenesis, ammonia is a poor biomarker for HE, in the context of CLD. More than $80 \%$ of cirrhotic patients with HE present elevated serum ammonia levels [8], however that also occurs in $30-60 \%$ of cirrhotic patients without HE [9]. Furthermore, correlations between ammonia level and severity of HE are only weak and inconsistent, with wide variation of levels, important overlap between grades of $\mathrm{HE}$, and with no clear cut-off to discriminate severe HE [8]. Many factors can hamper the acuity of ammonia for HE: technical aspects, individual susceptibility and environmental factors. Regarding technical aspects, the way blood is collected influences ammonia measurement, and it should be avoided fist clenching and tourniquet use. Furthermore, the sample should be immediately placed on ice and centrifuged within $15 \mathrm{~min}$ of collection, since if left at room temperature ammonia concentration can increase $20 \%$ within $1 \mathrm{~h}$ and up to $100 \%$ within $2 \mathrm{~h}$. Ammonia levels are also influenced by the patient age, exercise and smoking. Many conditions can also increase ammonia such as urea cycle disorders, urinary tract infections from urease-producing microorganisms, parenteral nutrition and some drugs such as valproic acid. Neurotoxicity of ammonia is also modulated by several factors such as muscle mass, kidney function, osmolarity, inflammation-induced increased bloodbrain barrier permeability, and genetic polymorphisms in enzymes of ammonia metabolism such as glutaminase gene [10].

A group in Valencia studied the toxic oxidant 3-nitrotyrosine as biomarker, the rationale being the known ability of hyperammonemia to induce oxidative stress. In fact, 3-nitro-tyrosine has been implicated as a toxin involved in the pathogenesis of HE. Their pilot study did show promising results, with 3-nitro-tyrosine higher than $14 \mathrm{nM}$ presenting almost $90 \%$ sensitivity, specificity, positive and negative predictive value for MHE [11]. Validation from other groups is needed.

Inflammation is another culprit in the pathogenesis of HE. In fact, circulating chemokines, cytokines, and ammonia itself can activate microglia, the resident macrophage-like cells of the brain, promoting neuroinflammation, further impairing brain function. Small studies measuring interleukin (IL)-18, and particularly IL-6 showed good correlations with the presence and severity of HE. IL-6 above $11 \mathrm{pg} / \mathrm{mL}$ seems a promising cut-off for MHE $[12,13]$.

Strebel et al. [14], in this issue of Portuguese Journal of Gastroenterology, studied 30 patients with liver cirrhosis, half with OHE and half with MHE, and evaluated two serum biomarkers, $S 100 \beta$ and neuron-specific enolase (NSE). They could not find a correlation with the severity of HE [14]. Furthermore, S100 $\beta$ and NSE levels did not change after treatment with L-ornithine and L-aspartate (LOLA), a probably efficient (albeit not routinely used) treatment for HE [15].

$\mathrm{S} 100 \beta$ is a $10.4 \mathrm{kDa}$ calcium-binding protein that has a role in cellular signal transduction and calcium homeostasis. In the brain, $\mathrm{S} 100 \beta$ is neurotrophic at the nanomolar level and neurotoxic at the micromolar level [16]. It was named S100 after being detected, in 1965, in high 
Fig. 1. Landscape of the current candidate biomarkers for hepatic encephalopathy. $\mathrm{HE}$, hepatic encephalopathy; MHE, minimal hepatic encephalopathy, ALF, acute liver failure.

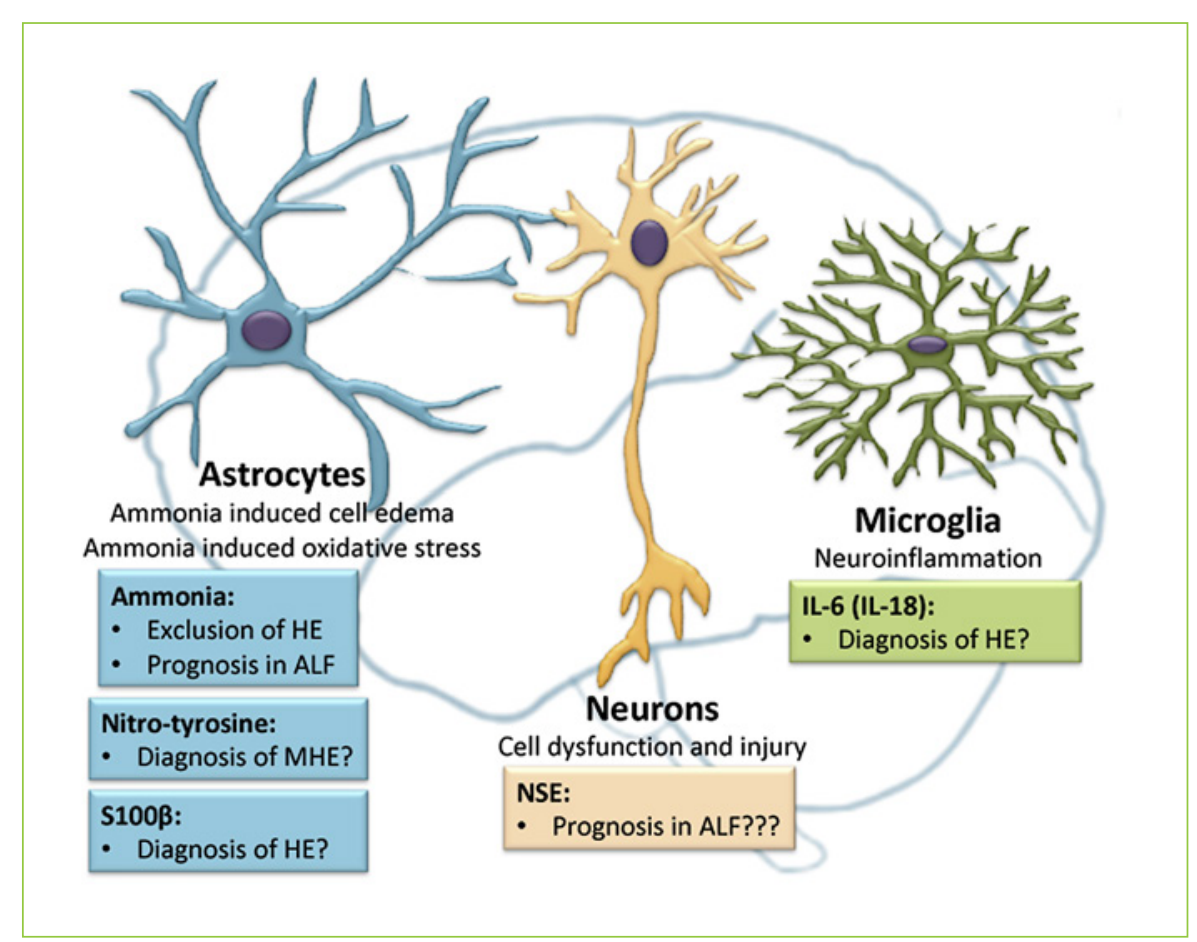

concentrations in brain factors from different mammals, and being soluble in $100 \%$ ammonium sulphate [17]. It is primarily synthesized in the brain by astrocytes, a target cell of hyperammonia neurotoxicity. S100 $\beta$ is not $100 \%$ brain-specific, since $10 \%$ is produced in other sources such as adipose tissue, skin and melanoma, as well as Tlymphocytes [16]. Normal serum levels of S100 $\beta$ are below $0.10 \mu \mathrm{g} / \mathrm{L}$; it is metabolized and excreted by the kidney and its expression does not seem to be influenced by ethnicity, gender or circadian rhythm, though it does seem to correlate with body mass index (BMI). S100 $\beta$ serum levels increase in different neurologic disorders, that course with damage and activation of astrocytes. Indeed, $S 100 \beta$ has been studied as a biomarker for different neuropsychiatric diseases such as trauma- and cardiac arrestinduced brain injury, ischemic stroke, sepsis-associated encephalopathy, epilepsy, schizophrenia, and CreutzfeldtJakob disease [18-21]. The most validated conditions are trauma-induced brain injury and ischemic stroke, from which we can learn precious information regarding the kinetics of $S 100 \beta$ elevation. After traumatic brain injury, there may be a peak at 3-6 h that correlates with mortality with high sensitivity; as such the Scandinavian guidelines recommend hospital discharge without CT-scan when $S 100 \beta$ is normal at $6 \mathrm{~h}$ [18]. A second peak of $S 100 \beta$ discriminates those patients with increased intracranial pressure and may help guide therapy [22]. After ischemic stroke, the peak in $S 100 \beta$ is a little later, and the best time point in predicting outcome is $48-72 \mathrm{~h} \mathrm{[19]}$. Some preliminary studies also studied the role of $S 100 \beta$ as a biomarker in HE, particularly in the context of acute liver failure (ALF). In ALF, S100 $\beta$ increased up to 3 fold on admission and until $72 \mathrm{~h}$; however, $S 100 \beta$ levels did not correlate with the severity of HE, development of brain herniation or outcome [23-26]. Two small studies in CLD found normal S100 $\beta$ levels in patients without HE, and a 2 -fold increase in patients with $\mathrm{HE}$, suggesting that levels higher than $0.13 \mu \mathrm{g} / \mathrm{L}$ achieve $83 \%$ sensitivity and $64 \%$ specificity for HE. S100 $\beta$ did not correlate with HE severity, being unable to discriminate OHE from MHE $[16,27]$.

NSE is an enzyme (2-phospho-D-glycerate hydrolyase) of the anaerobic glycolytic pathway, specific for neurons and neuroendocrine cells. As such, it is a tumor marker for small cells lung cancer and neuroendocrine tumors. NSE is also used as a prognostic factor in brain damage after cardiac arrest, stroke, and trauma-induced brain injury $[28,29]$. When measured in the 6 first hours post stroke, it has a strong positive correlation with infarct volume and negative with Glasgow coma scale. After cardiac arrest, NSE higher than $45 \mathrm{ng} / \mathrm{mL}$ at $48-72 \mathrm{~h}$ associates with worse neurological outcome, with a rate of 
false positive of only $5 \%$ [28]. NSE, as a biomarker of HE, has previously only been studied in the context of ACF, not in CLD. In pilot studies with ALF, NSE was not significantly increased, though there was a trend to higher levels in patients who developed central herniation compared to survivors $[23,26]$.

The study by Strebel et al. [14] comes out as a negative study; however, we must keep in mind some limitations of the study. First, it is a very small pilot study with less than 30 patients finishing the study. Second, it lacks two control groups: subjects without cirrhosis and patients with cirrhosis without HE. Third, there are some concerns regarding the accurate diagnosis of $\mathrm{HE}$, since only $33 \%$ of the patients had increased ammonia level, either OHE or MHE, which is much lower than expected. As such, we cannot access how S100 $\beta$ and NSE perform as biomarkers for the diagnosis of HE. Having said that, two-third of patients presented increased levels of $S 100 \beta$ ( $80 \%$ for patients with OHE), whereas only 1 out of 5 presented increased levels of NSE. The authors did not find a correlation between S100 $\beta / \mathrm{NSE}$ and severity of HE; however, the West-Haven scale is subjective with high inter-observer and intra-observer variability, and psychometric tests are affected by patient's age and education. The authors also did not find variations on $S 100 \beta /$ NSE after treatment with LOLA. Again, this result is dif- ficult to interpret, since LOLA treatment did not associate with a decrease in ammonia, as it would be expected [15]. Lastly, biomarkers levels were not adjusted for confounding variables, such as BMI, and the precipitating factors for $\mathrm{HE}$ that were excluded were not thoroughly described. It could also be a matter of timing of collection after the beginning of HE.

The present study, integrated in the previous literature, suggests that the role of $S 100 \beta$ in the diagnosis of $\mathrm{HE}$ might be worthwhile further investigation, although it does not seem to be a good biomarker for grading $\mathrm{HE}$ and monitor therapy. NSE seems a much less promising candidate biomarker for HE in CLD, although it might have a role in evaluating patients with ALF too sick for liver transplantation (Fig. 1).

\section{Conflict of Interest Statement}

The author has no conflicts of interest to declare.

\section{Funding Sources}

The author did not receive funding for this manuscript preparation.

\section{References}

1 Vilstrup H, Amodio P, Bajaj J, Cordoba J, Ferenci $\mathrm{P}$, Mullen KD, et al. Hepatic encephalopathy in chronic liver disease: 2014 Practice Guideline by the American Association for the Study of Liver Diseases and the European Association for the Study of the Liver. Hepatology. 2014 Aug;60(2):715-35.

2 Karanfilian BV, Park T, Senatore F, Rustgi VK. Minimal Hepatic Encephalopathy. Clin Liver Dis. 2020 May;24(2):209-18.

3 Ampuero J, Simón M, Montoliú C, Jover R, Serra MÁ, Córdoba J, et al. Minimal hepatic encephalopathy and critical flicker frequency are associated with survival of patients with cirrhosis. Gastroenterology. 2015 Nov;149(6): 1483-9.

4 Kumral D, Qayyum R, Roseff S, Sterling RK, Siddiqui MS. Adherence to Recommended Inpatient Hepatic Encephalopathy Workup. J Hosp Med. 2019 Mar;14(3):157-60.

5 Haj M, Rockey DC. Ammonia Levels Do Not Guide Clinical Management of Patients With Hepatic Encephalopathy Caused by Cirrhosis. Am J Gastroenterol. 2019. https://doi. org/10.14309/ajg.0000000000000343.

6 Shawcross DL, Olde Damink SW, Butterworth RF, Jalan R. Ammonia and hepatic en- cephalopathy: the more things change, the more they remain the same. Metab Brain Dis. 2005 Sep;20(3):169-79.

7 Cauli O, Rodrigo R, Lansdale M, Montoliu C, Monfort P, Piedrafita B, et al. Glutamatergic and gabaergic neurotransmission and neuronal circuits in hepatic encephalopathy. Metab Brain Dis. 2009 Mar;24(1):69-80.

8 Qureshi MO, Khokhar N, Shafqat F. Ammonia levels and the severity of hepatic encephalopathy. J Coll Physicians Surg Pak. 2014 Mar; 24(3):160-3.

9 Ong JP, Aggarwal A, Krieger D, Easley KA, Karafa MT, Van Lente F, et al. Correlation between ammonia levels and the severity of hepatic encephalopathy. Am J Med. 2003 Feb; 114(3):188-93.

10 Romero-Gómez M, Jover M, Del Campo JA, Royo JL, Hoyas E, Galán JJ, et al. Variations in the promoter region of the glutaminase gene and the development of hepatic encephalopathy in patients with cirrhosis: a cohort study. Ann Intern Med. 2010 Sep;153(5):281-8.

11 Montoliu C, Cauli O, Urios A, ElMlili N, Serra MA, Giner-Duran R, et al. 3-nitro-tyrosine as a peripheral biomarker of minimal hepatic encephalopathy in patients with liver cirrho- sis. Am J Gastroenterol. 2011 Sep;106(9): 1629-37.

12 Genesca J, Gonzalez A, Segura R, Catalan R, Marti R, Varela E, et al. Interleukin-6, nitric oxide, and the clinical and hemodynamic alterations of patients with liver cirrhosis. Am J Gastroenterol. 1999 Jan;94(1):169-77.

13 Montoliu C, Piedrafita B, Serra MA, del Olmo JA, Urios A, Rodrigo JM, et al. IL-6 and IL-18 in blood may discriminate cirrhotic patients with and without minimal hepatic encephalopathy. J Clin Gastroenterol. 2009 Mar; 43(3):272-9.

14 Strebel H, Haller B, Sohn M, Schepp W, Gundling F. Role of brain biomarkers S100-beta and Neuron specific enolase for detection and follow-up of hepatic encephalopathy in cirrhosis before, during and after therapy with L-ornithine L-aspartate. GE J Port Gastroenterol; $2020 . \quad$ https://doi. org/10.1159/000507225.

15 Goh ET, Stokes CS, Sidhu SS, Vilstrup H, Gluud LL, Morgan MY. L-ornithine L-aspartate for prevention and treatment of hepatic encephalopathy in people with cirrhosis. Cochrane Database Syst Rev. 2018 May; 5:CD012410 
16 Duarte-Rojo A, Ruiz-Margáin A, Macias-Rodriguez RU, Cubero FJ, Estradas-Trujillo J, Muñoz-Fuentes RM, et al. Clinical scenarios for the use of $S 100 \beta$ as a marker of hepatic encephalopathy. World J Gastroenterol. 2016 May;22(17):4397-402.

17 Moore BW. A soluble protein characteristic of the nervous system. Biochem Biophys Res Commun. 1965 Jun;19(6):739-44.

18 Undén J, Ingebrigtsen T, Romner B; Scandinavian Neurotrauma Committee (SNC). Scandinavian guidelines for initial management of minimal, mild and moderate head injuries in adults: an evidence and consensus-based update. BMC Med. 2013 Feb; 11(1):50.

19 Foerch C, Singer OC, Neumann-Haefelin T, du Mesnil de Rochemont R, Steinmetz H, Sitzer M. Evaluation of serum S100B as a surrogate marker for long-term outcome and infarct volume in acute middle cerebral artery infarction. Arch Neurol. 2005 Jul;62(7):11304.

20 Yao B, Zhang LN, Ai YH, Liu ZY, Huang L. Serum $S 100 \beta$ is a better biomarker than neu- ron-specific enolase for sepsis-associated encephalopathy and determining its prognosis: a prospective and observational study. Neurochem Res. 2014 Jul;39(7):1263-9.

21 Otto M, Wiltfang J, Schütz E, Zerr I, Otto A, Pfahlberg A, et al. Diagnosis of CreutzfeldtJakob disease by measurement of S100 protein in serum: prospective case-control study. BMJ. 1998 Feb;316(7131):577-82.

22 Sen J, Belli A. S100B in neuropathologic states: the CRP of the brain? J Neurosci Res. 2007 May;85(7):1373-80.

23 Strauss GI, Christiansen M, Møller K, Clemmesen JO, Larsen FS, Knudsen GM. S-100b and neuron-specific enolase in patients with fulminant hepatic failure. Liver Transpl. 2001 Nov;7(11):964-70.

24 Isobe-Harima Y, Terai S, Segawa M, Uchida K, Yamasaki T, Sakaida I. Serum S100b (astrocyte-specific protein) is a useful marker of hepatic encephalopathy in patients with fulminant hepatitis. Liver Int. 2008 Jan;28(1): 146-7.

25 Vaquero J, Jordano Q, Lee WM, Blei AT, Group US; US Acute Liver Failure Study
Group. Serum protein S-100b in acute liver failure: Results of the US Acute Liver Failure Study group. Liver Transpl. 2003 Aug;9(8): 887-8.

26 Toney NA, Bell MJ, Belle SH, Hardison RM, Rodriguez-Baez N, Loomes KM, et al.; Pediatric Acute Liver Failure Study Group. Hepatic Encephalopathy in Children With Acute Liver Failure: Utility of Serum Neuromarkers. J Pediatr Gastroenterol Nutr. 2019 Jul;69(1): 108-15.

27 Wiltfang J, Nolte W, Otto M, Wildberg J, Bahn E, Figulla HR, et al. Elevated serum levels of astroglial S100beta in patients with liver cirrhosis indicate early and subclinical portalsystemic encephalopathy. Metab Brain Dis. 1999 Dec;14(4):239-51.

28 Stammet P. Blood Biomarkers of HypoxicIschemic Brain Injury after Cardiac Arrest. Semin Neurol. 2017 Feb;37(1):75-80.

29 Cheng F, Yuan Q, Yang J, Wang W, Liu H. The prognostic value of serum neuron-specific enolase in traumatic brain injury: systematic review and meta-analysis. PLoS One. 2014 Sep;9(9):e106680. 